Revista de
Economild
Contemporâned

\title{
O NOVO CONSENSO EM MACROECONOMIA NO BRASIL: A POLÍTICA FISCAL DO PLANO REAL AO SEGUNDO GOVERNO LULA
}

\author{
Flávio Arantes ${ }^{a}$ \\ Francisco Luiz Cazeiro Lopreato ${ }^{b}$

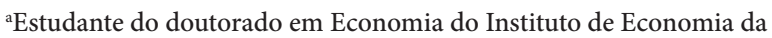 \\ Universidade Estadual de Campinas (IE-UNICAMP). \\ bProfessor Livre-Docente do IE-UNICAMP.
}

Artigo recebido em 16/10/2015 e aprovado em 13/12/2017.

RESUMO: A política fiscal do Plano Real seguiu a lógica do Novo Consenso em Macroeconomia. Desde o Plano criaram-se as bases para uma mudança do regime fiscal brasileiro em que a política fiscal deve preocupar-se com a sustentabilidade das contas públicas, garantindo aos agentes um ambiente estável para tomada de decisão. O regime é consolidado a partir da crise de 1999, com a adoção do tripé de câmbio flexível, metas de inflação e geração de superavit primário. O governo Lula aprofunda a condução da política fiscal nesses moldes até 2006, quando promove mudanças na sua base teórica e na sua condução. Desde então, embora mantenha características da fase anterior, a política fiscal sofreu alterações, com o Estado agindo mais diretamente na economia. Depois de contar com o "aval" da crise mundial de 2008, o ativismo do governo voltou a enfrentar resistência teórica por parte dos críticos presos ao Novo Consenso.

PALAVRAS-CHAVE: política fiscal; Novo Consenso; Plano Real; governo Lula.

CLASSIFICAÇÃO JEL: E62; E63; E65.

Correspondência para: Flávio Arantes

Contato: flarantes@gmail.com 


\title{
NEW MACROECONOMIC CONSENSUS IN BRAZIL: FISCAL POLICY FROM THE REAL PLAN TOPRESIDENT LULA'S SECOND MANDATE
}

\begin{abstract}
Fiscal policy implemented in Brazil at Real Plan followed the New Macroeconomic Consensus' logic. The Plan started the changing of Brazilian's fiscal regime into one in which fiscal policy must be confined to insuring a stable macroeconomic environment so private agents can make their decision. The regime is consolidated in 1999 crisis, when the tripod was adopted: flexible exchange rates, inflation targeting and primary fiscal surplus. Lula's mandate deepens the conduction of fiscal policy accordingly until 2006, when it suffers a substantial change, both in its theoretical basement and in its implementation. Since then, Brazilian government has been more active over the economy, although fiscal policy keeps relevant characteristics of the previous phase. The 2008 world crisis endorsed the activism, but since the acute phase of the crisis is over, the sympathetic critics to the New Macroeconomics ideas have put hard theoretical and political resistances to the measures adopted.
\end{abstract}

KEYWORDS: fiscal policy; New Consensus; Real Plan; Lula government. 


\section{INTRODUÇÃO}

Esse artigo tem o objetivo de mostrar como a política fiscal implementada no Brasil no Plano Real seguiu a lógica teórica do modelo de condução da política macroeconômica que se convencionou chamar de Novo Consenso em Macroeconomia. O argumento é que, a partir do Plano Real, criaram-se as bases para uma mudança do regime fiscal brasileiro em que a política fiscal deve preocupar-se com a sustentabilidade das contas públicas para garantir aos agentes do mercado um ambiente estável para a tomada de decisão. O novo regime fiscal é consolidado a partir da crise cambial de 1999, juntamente com a adoção do regime de política macroeconômica baseado no tripé de câmbio flexível, metas de inflação controladas pelo ajuste na taxa de juros básica da economia e geração de superavit primário na área fiscal.

Defendemos ainda que o governo Lula manteve e aprofundou a condução da política fiscal segundo o modelo teórico dominante até 2006, ano em que promoveu mudanças na sua base teórica e no seu modo de condução. A partir daí, a política fiscal, embora mantenha características da fase anterior, sofreu alterações relevantes e se comprometeu com ações mais diretas sobre a economia, com o Estado retomando o papel de fomentar o crescimento econômico e o desenvolvimento social. Por fim, mostramos que a mudança da política fiscal, depois de contar com o "aval" da crise econômica mundial de 2008, voltou a enfrentar resistência teórica por parte dos críticos presos ao pensamento convencional do Novo Consenso.

Para cumprir com esses objetivos o trabalho é divido em cinco seções, além dessa introdução e das considerações finais. Na seção que segue, mostramos em termos teóricos o Novo Consenso em Macroeconomia, apresentando o modelo adotado para a condução da política macroeconômica e atendo à discussão do papel da política fiscal segundo essa visão. Em seguida, discutimos o caso brasileiro, com base na mudança do regime fiscal em meados dos anos 1990 e sua consolidação no final da década para, na sequência, mostrar como o governo Lula o aprofundou nos primeiros anos do mandato. Essa é a tarefa das seções dois, três e quatro, respectivamente. Na quinta seção, apresentamos as mudanças na condução da política fiscal, que marcaram o período a partir de 2006 para colocar algumas considerações sobre o regime fiscal, à guisa de conclusão.

\section{POLÍTICA MACROECONÔMICA E O PAPEL DA POLÍTICA FISCAL}

A política macroeconômica adotada no Brasil desde meados dos anos 1990 tem como base teórica as premissas do consenso formado entre duas das principais correntes de pensamento ortodoxo, que dominaram o debate macroeconômico ao longo dos anos 
1980. De acordo com Woodford (2008), há uma convergência de opinião e relativa ausência de desentendimentos com relação aos princípios básicos da macroeconomia que se convencionou chamar de Nova Síntese Neoclássica (GOODFRIEND e KING, 1997) ou Novo Consenso em Macroeconomia (MEYER, 2001; ARESTIS e SAWYER, 2002). Trata-se de um Novo Consenso em Macroeconomia (NCM) por reunir num arcabouço teórico comum as contribuições da escola Novo-Clássica com as críticas e propostas dos Novos Keynesianos - principais expoentes do pensamento mainstream em macroeconomia desde os anos 1980. Na base desse arcabouço estão incorporadas a otimização intertemporal e as expectativas racionais nos modelos macroeconômicos dinâmicos, oriundas dos Novos Clássicos e dos modelos dos ciclos reais de negócios, juntamente com a concorrência imperfeita e rigidez de preços e salários, dos Novos Keynesianos (GOODFRIEND e KING, 1997).

O NCM utiliza-se de modelos macroeconômicos de equilíbrio geral intertemporal e que possam ser validados econometricamente. De um lado, advoga que a estrutura intertemporal permite analisar, num mesmo ferramental, tanto as questões relacionadas às flutuações da economia (curto prazo), quanto as de crescimento econômico (longo prazo). De outro lado, a validação significa que, ao mesmo tempo em que usa técnicas econométricas para a estimação dos parâmetros estruturais do modelo, há também simulação das políticas econômicas, para testar qual modelo tem a geração de dados que mais se assemelha ao que é previsto para as séries temporais (WOODFORD, 2008). Uma característica importante dessas análises é que o NCM utiliza modelos simples, abstratos e com uma relativamente pequena quantidade de dados para elucidar mecanismos macroeconômicos mais complexos (KING, 1995).

Os modelos do NCM também refletem a "crítica de Lucas" (LUCAS, 1976), no sentido de que as expectativas dos agentes devem ser consideradas como endógenas. Isso significa que, quando analisadas as políticas macroeconômicas, deve-se considerar que as expectativas mudam conforme a escolha de política feita. Em outros termos, o processo de modelagem torna-se dinâmico, pois a cada decisão de política tomada os parâmetros do modelo mudam, uma vez que os agentes ajustam suas expectativas ao novo cenário que encontram. Além disso, é amplamente aceito no NCM que distúrbios reais são uma fonte importante para as flutuações econômicas. Estes distúrbios não se devem apenas a mudanças na produtividade, mas também nas preferências (mudanças nos parâmetros) e nas políticas governamentais (como ações da política fiscal nas condições de oferta). A oferta agregada sofre alterações, uma vez que os choques não apenas desviam o produto de sua taxa natural ${ }^{1}$, como têm a

\footnotetext{
O NCM trabalha com a hipótese da taxa de desemprego que não acelera a inflação, a NAIRU ("non-accelerating inflation rate of unemployment"), determinada pelas características estruturais dos mercados de bens e de trabalho e que expressa a taxa real de "desemprego de equilíbrio".
} 
capacidade de alterar a própria taxa natural (choques reais deslocam a tendência de longo prazo). No lado da demanda, os modelos do NCM não aceitam o market clearing, da visão novo-clássica, e trabalham com a hipótese de que há rigidez de preços e salários, de modo que há espaço para a atuação da política econômica. Se preços e salários se ajustassem imediatamente às variações da demanda agregada, a economia se moveria sobre a curva de oferta agregada de longo prazo (vertical) e a taxa de desemprego ficaria em seu "nível natural".

A convergência metodológica do NCM pode ser expressa num modelo padrão de três equações e três incógnitas, usado como ferramental básico para a proposição e condução da política macroeconômica ${ }^{2}$ :

$$
\begin{gathered}
(y-\hat{\mathrm{y}})_{t}=a_{0}+a_{1}(y-\hat{\mathrm{y}})_{t-1}+a_{2} E_{t}(y-\hat{\mathrm{y}})_{t+1}+a_{3}\left(i_{t}-E_{t}\left(\pi_{t+1}\right)\right)+s_{1} \\
\pi_{t}=b_{1} \pi_{t-1}+b_{2} E_{t}\left(\pi_{t+1}\right)+b_{3}(y-\hat{\mathrm{y}})_{t}+s_{2} \\
i_{t}=r^{*}+c_{1}\left(\pi_{t}-\pi^{T}\right)+c_{2}(y-\hat{\mathrm{y}})_{t}
\end{gathered}
$$

Nas equações (1), (2) e (3), $(y-\hat{y})$ é o hiato de produto, sendo $y$ o produto corrente e $\hat{y}$ o produto potencial da economia; $E_{t}$ é o operador de expectativas; $\pi$ é a inflação, $\pi^{T}$ é a meta de inflação; $i$ é a taxa nominal de juros controlada pelo Banco Central (BC) e $r *$ é a taxa de juros real de equilíbrio; $a_{3}<0$ e $a_{0}$ é uma constante que indica efeitos exógenos; $b_{1}+b_{2}=1, b_{3}>0 ; c_{1}>1, c_{2}>0 ;$ e $s_{1}$ e $s_{2}$ representam choques aleatórios.

As equações descrevem uma "curva do tipo IS" (1) (BLANCHARD, 2008), uma "curva de Phillips" (2) e uma "regra de Taylor padrão" (3) (TAYLOR, 1993), em que as incógnitas são o produto corrente da economia, a inflação e o nível da taxa de juros nominal (de referência, ou básica da economia). A solução do modelo leva em consideração os objetivos macroeconômicos de estabilidade do produto e dos preços que são atingidos quando o hiato de produto zera e a inflação se iguala à meta estabele-

2 O modelo usado aqui possui a mesma estrutura daqueles apresentados em Arestis e Sawyer (2002), Arestis (2007), Carlin e Soskice (2006), Tcherneva (2008) e Fontana (2009a). Entretanto, as primeiras apresentações do modelo se encontram em Clarida et al. (1999), McCallum (2001), Meyer (2001) e Woodford (2003). 
cida ${ }^{3}$. Para que isso seja possível, a variável de ajuste é a taxa de juros nominal da economia, como determinada na equação (3).

Não existe papel para a oferta de moeda ${ }^{4}$ no modelo do NCM e pouca atenção se dá ao processo de criação e destruição de liquidez no sistema, de maneira que a discussão da política monetária limita-se à determinação da taxa de juros do $\mathrm{BC}$ segundo a regra de Taylor por ele utilizada ${ }^{5}$. $\mathrm{O}$ ajuste da taxa de juros tornou-se o único instrumento da política monetária, buscando responder às variações no hiato de produto a fim de atingir meta de inflação ${ }^{6}$. Tampouco se discute a atuação da política físcal como instrumento de estabilização ${ }^{7}$. No modelo básico do NCM a política fiscal é predeterminada (a constante $a_{0}$ ) ou representa um choque exógeno $\left(s_{1}\right)$ e o seu papel primordial é manter a sustentabilidade da dívida como meio de garantir a eficiência da política monetária - livre de dominância fiscal (SARGENT e WALLACE, 1981) - no controle da inflação ${ }^{8}$.

Uma série de argumentos teóricos e empíricos justifica, para o mainstream, o preterimento da política fiscal em favor da política monetária. Tais argumentos vão desde a proposição da Teoria da Equivalência Ricardiana, em Barro (1974); passam pelas

3 Com a hipótese da NAIRU, o nível de preços é resultado direto dos fatores que determinam tanto a oferta quanto a demanda agregada: qualquer choque em pelo menos um dos lados implica um novo nível de preços no equilíbrio no mercado de trabalho. Como não há ajuste imediato, a atividade econômica flutua em torno da NAIRU. A inflação aumenta quando o desemprego cai abaixo da NAIRU e se acelera caso a taxa de desemprego seja mantida num nível abaixo da NAIRU. Não há "trade-off" entre desemprego e inflação no longo prazo, de maneira que, se é o objetivo econômico que a inflação se mantenha estável, a economia deve operar, na média, próxima à NAIRU. No longo prazo, a inflação é vista apenas como um fenômeno monetário cuja trajetória pode ser influenciada pelos ajustes na taxa de juros. Ver Arestis e Sawyer (2002; 2003a), Calin e Soskice (2006) e Santos (2011).

4 Arestis e Sawyer (2003a) argumentam que a ausência de uma equação que relacione oferta e demanda por moeda no modelo do NCM é consequência direta do pressuposto da neutralidade da moeda.

5 A taxa de juros é ajustada em busca da taxa de juros real que representa a taxa de equilíbrio da economia, influenciada pelos desvios da inflação de sua meta e do produto de seu nível potencial (ou da sua "tendência natural"). Para o NCM, quando o BC ajusta a taxa de referência no seu nível de "equilíbrio real", investimento e poupança tornam-se iguais e o equilíbrio agregado (de emprego e/ou produto) é atingido (ARESTIS e SAWYER, 2003a).

6 A regra de Taylor é a maior expressão do NCM para a proposição de política macroeconômica e, para agir livremente em busca da estabilidade do produto e dos preços, o BC precisa ser independente e se guiar por um regime de metas de inflação (condizentes com a NAIRU).

7 Para Arestis e Sawyer (2002), Tcherneva (2008) e Fontana (2009a), entre outros, o NCM pode ser sintetizado pela elevação ("upgrade") do papel atribuído à política monetária e pelo consequente rebaixamento ("downgrade") da política fiscal.

8 É preciso frisar que é pressuposto que a política monetária não reaja à política fiscal. Na maior parte da literatura mainstream que analisa as interações entre política monetária e fiscal e em que a inflação é objetivo macroeconômico, a política fiscal sempre reage à política monetária e não o contrário. Ver, a respeito, Kirsanova et al. (2005), Leeper (1991) e Leeper e Walker (2013). 
diversas sortes de crowding out dos gastos privados e pela discussão das defasagens (“lags”) de implementação da política, presentes desde Friedman (1968); e culminam nos argumentos de natureza ideológica e política, contrários à intervenção do governo no ajuste econômico, como ressaltam Blinder (2004), Solow (2005), Fontana (2009b) e Forder (2007).

Apesar de não haver uma teoria consolidada ou uma visão unificada no NCM, a abordagem sobre a política fiscal remonta aos pressupostos fundamentais da visão novo-clássica. A discussão com base nos argumentos da "crítica de Lucas" e da literatura sobre time-consistency levou os autores da visão convencional a formar relativo consenso sobre as possíveis vantagens da adoção de regras na condução da política monetária ${ }^{9}$ e a abandonar as ações específicas de administração da demanda agregada. Os autores do NCM acataram a ideia de que os dirigentes econômicos devem estar comprometidos com as "regras do jogo" ou com " $a$ " estratégia de política econômica capaz de, a cada período, validar as expectativas dos agentes e garantir os resultados macroeconômicos desejados. A política fiscal passou a desempenhar a tarefa de fiadora da estabilidade macroeconômica e a estar sujeita a regras em condições de garantir credibilidade ao comportamento do setor público e assegurar a sustentabilidade das contas públicas ${ }^{10}$.

A discussão da solvência do setor público remete à sustentabilidade da dívida pública, medida pelo indicador dívida/PIB, e parte da restrição orçamentária do governo:

$$
D=G-T+i B=\Delta B+\Delta H
$$

Em (4), $D$ é o deficit; $G$, os gastos públicos; $T$, a arrecadação tributária; $B$, o estoque de dívida; e $i$ é a taxa de juros - todos em valores nominais.

A equação indica que os deficit públicos devem ser financiados pela variação no estoque de dívida pública ( $\Delta B$ ) ou pela senhoriagem ( $\Delta H$ ). Desconsiderando o papel da senhoriagem, tanto por simplicidade quanto por ser desprezível nos sistemas financeiros desenvolvidos (ALLSOPP e VINES, 2005; LEEPER e WALKER, 2013), e considerando $Y_{t}$ como o produto da economia no período $t$, temos a equação de acúmulo de dívida em termos reais:

9 Ver, por exemplo, Kydland e Prescott (1977), Barro e Gordon (1983) e Taylor (1993).

${ }_{10}$ Allsop e Vines $(2005$, p. 486) partilham da argumentação de que a política fiscal tomou um lugar de garantidora da estabilidade econômica, e reconhecem que " $[\mathrm{t}]$ his assignment of roles and responsibilities means that the fiscal authorities can concentrate on such issues as the control and sustainability of the public finances as well as on the resource allocation and distributional effects of budgetary policy". 


$$
B_{t} / Y_{t}-B_{t-1} / Y_{t-1}=(r-g) * B_{t-1} / Y_{t-1}+(G-T) / Y_{t}
$$

Em (5), $r$ é a taxa de juros real $(i=r-\pi)$ e $g$ o crescimento real do produto. Com $B / Y=b$ e $(G-T) / Y=x$, temos a versão simplificada:

$$
\Delta b=b(r-g)+x
$$

Pela equação (6), sempre que a taxa média de crescimento do PIB diferir da taxa de juros real média incidente sobre a dívida, dado o resultado primário e ausência de senhoriagem, haverá variação da dívida no período posterior. Se $r<g$ e $|b(r-g)|>x$ a relação dívida/PIB se reduz ao longo do tempo e, se $|b(r-g)|=x$, ela permanece estável ( $\Delta b=0)$. Em ambos os casos, aos olhos do mercado, as finanças públicas são sustentáveis intertemporalmente. Contudo, se $r>g$ a dívida tende a aumentar ao longo do tempo, tornando a relação crescente. Na ausência de uma correção por meio de $x$, a variação na relação dívida/PIB cresce indefinidamente e sua sustentabilidade, vista pela ótica da solvência do setor público, fica comprometida ${ }^{11}$. Ou seja, a dívida é considerada sustentável caso o governo cumpra, no presente, a restrição orçamentária necessária para garantir sua estabilidade em relação ao PIB de maneira intertemporal.

Na prática, a sustentabilidade da dívida pública requer do governo a obrigação de ajustar o superavit primário, de modo a estabilizar a relação dívida/PIB. O esforço fiscal necessário está condicionado ao comportamento das variáveis macroeconômicas com reflexo direto na relação. Assim, a incorporação de novas dívidas, o declínio da taxa de crescimento esperado da economia, o aumento das taxas de juros incidentes sobre a dívida (fruto de alterações nos juros internos, nos juros internacionais ou no prêmio de risco da economia), ou o impacto da desvalorização da taxa de câmbio na dívida podem comprometer sua sustentabilidade e demandar o aumento do esforço fiscal para preservar sua solvência.

Neste regime de política econômica, as ações da política fiscal ficam submetidas ao comportamento daquelas variáveis que influenciam a trajetória da dívida e à volatilidade dos fluxos internacionais de capitais, fruto da avaliação do mercado sobre o risco de determinado País. A avaliação do mercado também passa pelas expectativas dos agentes com relação à própria condução da política. Meras percepções de que haverá uma deterioração permanente no resultado fiscal têm impacto sobre as taxas de juros e as condi-

11 Uma dívida sustentável na visão do NCM é aquela que não cresce desproporcionalmente com relação ao produto. 
ções de financiamento do governo, influenciando negativamente a trajetória da dívida; da mesma forma, aumentos momentâneos da dívida podem não implicar a caracterização de uma trajetória insustentável da política fiscal, "desde que mantida a política econômica e o compromisso com a disciplina fiscal" (GUARDIA, 2004, p. 108).

A esses pontos básicos das propostas de política macroeconômica dominante, somam-se, a partir de uma perspectiva mais ampla, os movimentos de liberalização financeira e comercial dos mercados globais, a defesa da livre movimentação de capitais e a predominância dos regimes de câmbio flutuante ${ }^{12}$. O comprometimento com o regime de política econômica e a estabilidade macroeconômica é condição necessária para os países terem acesso ao mercado internacional de capitais e assegurarem condições de crescimento.

A crise financeira mundial de 2008 explicitou as fragilidades do modelo do NCM e deu início à discussão de propostas no mainstream de alterações teóricas capazes de responder à realidade trazida pela crise. O debate está em curso, pleno de controvérsias. Até o momento, o eixo principal da argumentação pouco mudou, mas se acena com concessões relevantes. Blanchard et al. (2010) ${ }^{13}$ reconhecem, ao contrário da visão anterior, que a estabilidade inflacionária não é suficiente para garantir a estabilidade sistêmica e a taxa de juros em níveis baixos limita o raio de ação da política monetária em crises de deflação. Blanchard et al.(2013) e Blanchard e Summers (2017) apontam as limitações em usar a taxa de juros como único mecanismo de estabilização e a necessidade de incluir novos instrumentos para a execução da política monetária, bem como reconhecem a relevância da intermediação financeira e da regulação macroeconômica, ausentes na discussão do NCM. Por outro lado, cresceu a defesa em favor da revisão do papel da política fiscal ${ }^{14}$. Os autores citados acima defendem a necessidade de ampliar o espaço dessa política como ferramenta de estabilização, sobretudo, em condições de taxas de juros próximas de zero e sem perspectivas de alterações no curto prazo. Nestas condições é evidente a dificuldade de a política monetária responder sozinha à situação de crise e as medidas de política fiscal não sofreriam dos "lags" de implementação, dada a expectativa de duração da crise. Outros trabalhos incorporaram pressupostos "mais realistas" na modelagem como, por exemplo, a suspensão da hipótese da equivalência ricardiana, a redução do horizonte de tomada de

\footnotetext{
12 Ver Belluzzo (1995).

13 Esse artigo, do então economista chefe do Fundo Monetário Internacional (FMI), em parceria com demais integrantes do seu staff um artigo teve grande repercussão na academia e nos organismos multilaterais. Em 2013, com outras parcerias, Olivier Blanchard publicou nova discussão a respeito.

${ }^{14}$ O debate no imediato pós-crise pode ser acompanhado em detalhes em Santos (2011).
} 
decisão dos agentes e o reconhecimento da insuficiência da regra de Taylor em determinadas circunstâncias (EGGERTSSON, 2009; DEVEREUX, 2010). Ganhou força a ideia de que é importante as economias terem espaço fiscal para a execução de medidas fiscais de enfrentamento da crise (BLANCHARD et al., 2010; CLAESSENS et al., 2010; EICHENGREEN, 2012). Blanchard e Summers (2017) argumentam que a manutenção de taxas de juros inferiores à taxa de crescimento do PIB abre espaço para se repensar o debate sobre o alto nível de endividamento dos Países e a possibilidade de colocação de novos títulos públicos sem o risco de não comprometer sustentabilidade da dívida pública. Enfim, não há consenso em torno de como lidar com a política fiscal, mas, certamente, o papel totalmente subordinado que ocupava até a crise está a caminho de ser revisto.

\section{MUDANÇA NO REGIME FISCAL BRASILEIRO}

O controle da alta inflação com o Plano Real colocou a obrigação de repensar o setor público, em crise desde a crise da dívida externa do começo dos anos 1980. A recuperação da trajetória de crescimento da economia brasileira impunha reestruturar as condições de financiamento público e repensar o papel do Estado. Após os fracassos dos planos de estabilização ao longo dos anos 1980, o consenso era de que não se conseguiria uma estabilização monetária duradoura sem a implementação de reformas estruturais, sendo essas de ordem econômica, administrativa, previdenciária e tributária (TAVARES, 2005).

A partir das premissas do Plano Real instalou-se o processo de reformulação do regime fiscal brasileiro. O diagnóstico apresentado por Bacha (1994), baseado no conceito de deficit público potencial, constituiu ponto de inflexão nas propostas de estabilização anteriores e atribuiu ao deficit público a principal causa da inflação. A alta inflação, no entender do autor, era o meio pelo qual se tornava possível compatibilizar os valores previstos de receitas e despesas com um resultado manejável das contas públicas. O orçamento, embora equilibrado no conjunto de suas contas, embutia um "deficit potencial considerável em sua parte propriamente fiscal (no conceito operacional), devido tanto a uma subestimação das despesas como a uma superestimação das receitas" (BACHA, 1994, p. 9).

A consolidação fiscal permanente apresentava-se como um passo necessário para indicar aos investidores internacionais o comprometimento do País junto ao circuito de valorização do capital internacional. O Brasil precisava se mostrar comprometido com as políticas garantidoras da estabilidade, das variáveis macroeconômicas-chave e da capacidade dos agentes traçarem cenários e avaliarem os riscos de seus portfólios, bem como ganhar a confiança do mercado na manutenção das políticas vigentes. A 
condução da política fiscal deveria respeitar os princípios estabelecidos e definir um aparato institucional, baseado em regras, capaz de evitar a inconsistência intertemporal, de gerar o superavit primário necessário à solvência das contas públicas e de ganhar a confiança do mercado na manutenção das políticas vigentes ${ }^{15}$.

O Plano Real se propôs a redesenhar esse aparato e a formar um regime fiscal que atendesse às demandas tanto do ideário neoliberal quanto dos pressupostos da teoria macroeconômica dominante, do NCM. No primeiro estágio do Plano já são evidentes a ampla revisão do regime no sentido de garantir ao mercado o ajuste fiscal permanente e o comprometimento com a sua permanência intertemporal. O lançamento do Programa de Ação Imediata (PAI) visava ampliar e aperfeiçoar o controle das finanças públicas, o endividamento dos estados e municípios e reduzir o impacto fiscal das medidas que seriam tomadas no âmbito dos bancos públicos do País. As reformas propunham, no plano econômico, a redução do Estado, por meio da quebra do monopólio das estatais nos serviços de utilidade pública e de exploração de petróleo e maior abertura internacional, por meio do fim de restrições ao capital estrangeiro nas telecomunicações, energia e transporte. Do lado administrativo, o PAI pretendia eliminar os privilégios dos servidores públicos e aproximar os sistemas de benefícios e dos mecanismos de financiamentos dos Regimes Geral e Próprio da Previdência Social e defendeu propostas de reforma previdenciária, para reduzir o suposto deficit estrutural do Regime Geral (RGPS). Por fim, o programa também previa uma reforma tributária para simplificar o sistema, reduzir custos da administração tributária das empresas, aumentar a eficiência da arrecadação e desonerar exportações e investimentos (TAVARES, 2005).

Apesar da redução de escopo das propostas aprovadas no Congresso, o PAI conseguiu passos significativos em direção a um novo regime fiscal, uma vez que suas medidas eram consoantes ao pressuposto de que a dominância fiscal era a principal causa da instabilidade macroeconômica do País. Além das medidas "convencionais" de cortes de gastos e aumento da arrecadação, as privatizações, a nova estruturação do federalismo fiscal, o controle e saneamento dos bancos públicos ganharam lugar como medidas consideradas vitais ao restabelecimento da verdade orçamentária das contas da União e à definição da nova ordem fiscal.

O Plano Real seguiu a trilha traçada pelo PAI e defendeu ainda a independência do BC como forma de ganhar confiança na política de combate à inflação e mostrar o comprometimento em se livrar da dominância fiscal e de interferências políticas na condução da política monetária. Colocavam-se então os elementos que visavam, como defende o NCM, garantir a credibilidade intertemporal das políticas macroeconômicas adotadas em busca da estabilidade sistêmica.

15 Ver Lopreato (2013, cap. 4). 
A credibilidade no programa de reformas foi reforçada pelos resultados obtidos nos primeiros anos do Plano Real. A estratégia de juros altos e valorização do câmbio garantiu a âncora cambial e sua manutenção até quase o final do primeiro mandato do presidente Fernando Henrique Cardoso (FHC). Ao lado do comportamento do câmbio, o aumento da arrecadação tributária serviu para atenuar a forte pressão das altas taxas de juros sobre a dívida pública. Além disso, o Programa Nacional de Desestatização também influenciou positivamente a trajetória da dívida/PIB. Os recursos, da ordem de 5,8\% do PIB entre 1995 e 1998, aliados ao processo de monetização, favoreceram o movimento de resgate da dívida pública e reduziram, de certa forma, a necessidade de o governo elevar o esforço fiscal.

O período imediatamente posterior ao lançamento do Plano apresentou ainda outras condições favoráveis à avaliação positiva da economia brasileira pelo mercado. $\mathrm{O}$ bom comportamento do $\mathrm{PIB}^{16}$, a queda da taxa de juros após a crise do México de 1995, o processo de renegociação das dívidas dos governos subnacionais, junto ao encaminhamento das propostas de reforma tributária e da previdência social, indicaram perspectivas favoráveis de médio prazo e reforçaram a confiança nas condições de sustentabilidade da dívida pública.

Ademais, a confiança externa na economia brasileira era garantida pela possibilidade de financiamento do crescente deficit em transações correntes através da entrada maciça de capitais de curto prazo e dos investimentos externos diretos (IDE) atrelados às privatizações ${ }^{17}$. O resultado foi uma trajetória de dívida líquida do setor público sob relativo controle no período de 1994 a 1997, como a Tabela 1 mostra.

Tabela 1 - Dívida líquida do setor público, 1994-1998 (em \% PIB)

\begin{tabular}{lccccc}
\hline & $\mathbf{1 9 9 4}$ & $\mathbf{1 9 9 5}$ & $\mathbf{1 9 9 6}$ & $\mathbf{1 9 9 7}$ & $\mathbf{1 9 9 8}$ \\
\hline Gov. Federal e Bacen & 12,9 & 13,3 & 15,9 & 18,7 & 25,0 \\
Gov. Estaduais e Municipais & 10,0 & 10,6 & 11,5 & 12,9 & 14,2 \\
Empresas Estatais & 7,1 & 6,7 & 5,9 & 2,8 & 2,6 \\
Dívida Total & $\mathbf{3 0 , 0}$ & $\mathbf{3 0 , 6}$ & $\mathbf{3 3 , 3}$ & $\mathbf{3 4 , 4}$ & $\mathbf{4 1 , 7}$ \\
Interna & 21,3 & 25,0 & 29,4 & 30,1 & 35,5 \\
Externa & 8,7 & 5,6 & 3,9 & 4,3 & 6,2 \\
\hline
\end{tabular}

Fonte: Elaboração própria com base em dados de BACEN.

16 Com crescimento real de 5,3\% em 1994 e 4,4\% em 1995, segundo dados do IPEADATA.

17 Neste período, a existência de alta liquidez internacional somada à existência de ativos de elevada rentabilidade davam as condições para o ingresso de capitais na economia brasileira, confirmando a avaliação positiva dos agentes internacionais. 
Com o mercado avaliando positivamente a situação fiscal brasileira, o certo relaxamento apresentado na obtenção dos resultados primários a partir de 1995 não colocou em risco a sustentação intertemporal das contas públicas e nem a manutenção da "âncora cambial”. O declínio no superavit primário e o pequeno aumento da relação dívida/PIB não comprometeram, de imediato, as expectativas dos investidores internacionais.

Tabela 2 - Necessidades de financiamento do setor público, 1994-1998 (em \% PIB)

\begin{tabular}{llllll}
\hline & $\mathbf{1 9 9 4}$ & $\mathbf{1 9 9 5}$ & $\mathbf{1 9 9 6}$ & $\mathbf{1 9 9 7}$ & $\mathbf{1 9 9 8}$ \\
\hline Nominal & 26,97 & 7,27 & 5,86 & 6,07 & 7,47 \\
Juros Nominais & 32,18 & 7,54 & 5,77 & 5,10 & 7,49 \\
Primário & $\mathbf{- 5 , 2 1}$ & $\mathbf{- 0 , 2 7}$ & $\mathbf{0 , 0 7}$ & $\mathbf{0 , 9 5}$ & $\mathbf{- 0 , 0 1}$ \\
Gov. Federal e Bacen & $-3,25$ & $-0,52$ & 0,00 & 0,27 & $-0,55$ \\
Gov. Estaduais e Municipais & $-0,77$ & 0,18 & $-0,07$ & 0,74 & 0,19 \\
Empresas Estatais & $-1,19$ & 0,07 & 0,14 & $-0,06$ & 0,35 \\
\hline
\end{tabular}

Fonte: Elaboração própria com base em dados de BACEN.

É possível afirmar que, do lançamento do Plano até meados de 1997, a estratégia de juros elevados e câmbio valorizado "permitiu consolidar o processo de estabilização e contornar o problema do desequilíbrio externo mediante a atração de capitais estrangeiros" (GUARDIA, 2004, p. 110-111). Apesar das demonstrações institucionais de compromisso com a sustentabilidade das contas públicas e com o ajuste fiscal intertemporal, o esforço fiscal necessário para estabilizar a relação dívida/PIB neste período foi reduzido porque o contexto macroeconômico até 1997 foi favorável às expectativas dos agentes, o que ainda justificava o gradualismo no combate ao desequilíbrio das contas públicas por parte do governo.

O processo de consolidação de fato de um novo regime fiscal, da maneira pensada pela teoria dominante, baseado na criação de regras fiscais rígidas para regular as ações governamentais em todos os seus níveis e definir um comportamento condizente com a sustentabilidade das contas veio de maneira acelerada, fruto da necessidade de se socorrer a economia brasileira dos impactos das crises dos emergentes - Ásia e Rússia ${ }^{18}$. Frente à reversão do ciclo de liquidez internacional e à dificuldade em manter o finan-

${ }^{18}$ Dependentes do financiamento externo e do uso de títulos públicos como atrativo para a valorização da riqueza privada e diante das oscilações cambiais e da obrigação de manter taxas de juros diferenciadas perante as divisas-chave internacionais, as economias emergentes enfrentam o dilema de ter que garantir a sustentabilidade da dívida e correr o risco da fuga de capitais com o consequente impacto no financiamento do Balanço de Pagamentos e nas taxas de câmbio. 
ciamento do Balanço de Pagamentos, o BC brasileiro elevou subitamente a taxa de juros básica que, entretanto, foi insuficiente para atrair os capitais externos. Combinado com o crescimento medíocre do PIB e com a ausência de superavit primários significativos, a resposta monetária culminou na explosão da dívida pública, que passou de $34,4 \%$ do PIB em 1997 para 41,7\% em $1998^{19}$.

Essa rápida e significativa elevação da dívida colocou em xeque a sustentabilidade intertemporal das contas públicas e o papel da política fiscal como fiadora da estabilidade macroeconômica, justificando, para o governo, a ampliação do esforço fiscal necessário para conter o risco de insolvência da dívida pública. Como forma de compensar o aumento da despesa financeira devido à elevação da carga de juros e mostrar o comprometimento em ajustar as contas públicas, o governo passou a defender o aumento do resultado primário. A primeira medida nesse sentido foi a edição de um decreto $^{20}$ de contingenciamento de $\mathrm{R} \$ 4$ bilhões de custeio e investimento em setembro de 1998 - esforço nada desprezível no controle dos gastos, já que faltavam apenas quatro meses para o encerramento do exercício. $\mathrm{O}$ decreto também iniciou a prática de definição de metas claras e transparentes de resultados primários a serem buscados pela política fiscal (GUARDIA, 2004).

O compromisso com a sustentabilidade das contas públicas seria demonstrado pelo reforço da ideia de ajuste estrutural do setor público, pela retomada de projetos de aperfeiçoamento do arranjo institucional-legal, pela formalização de compromissos e estabelecimento de regras e limites fiscais em leis ordinárias e pela insistência em pontos das reformas administrativa e previdenciária que ainda não haviam sido equacionados em rodada anterior (TAVARES, 2005). O maior enrijecimento e a formalização da mudança de orientação da política fiscal vieram através da medida provisória $n^{\circ}$ 1.716 de 08/09/1998, que definiu a meta de superavit primário para 1999 e o prazo de até 15/11/1998 para a formulação de um Programa de Estabilidade Fiscal (PEF), para habilitar o País ao acesso aos recursos do Fundo Monetário Internacional (FMI). O PEF previa mudanças estruturais, avanços institucionais-legais e estabilização da dí-

19 Em novembro de 1997, o governo anunciou o pacote de "Medidas de Ajuste Fiscal e Competitividade", o famoso "Pacote 51", propondo reduzir gastos e aumentar arrecadação, na tentativa de realizar o ajuste fiscal já em 1998. Enquanto do lado dos gastos as principais medidas se relacionavam principalmente à demissão de funcionários públicos não estáveis, à suspensão dos reajustes salariais e aos cortes do investimento público federal, do lado da arrecadação se destacavam a elevação das alíquotas do imposto de renda da pessoa física, o aumento dos impostos sobre automóveis e a elevação dos preços dos derivados de petróleo e álcool. Contudo, como Filgueiras (2000) aponta, as medidas não cumpriram seus objetivos, algumas nem saíram do papel e a situação das contas públicas piorou ainda mais quando do aumento da taxa de juros.

${ }^{20}$ Decreto n$^{\circ} 2.773$, de 8 de setembro de 1998 . 
vida/PIB, em consonância com as diretrizes do $\mathrm{FMI}^{21}$. A estratégia do ajuste fiscal deveria implicar primeiramente num rápido ajuste dos fluxos de receitas e despesas da União $^{22}$, com vistas à geração de superavit primário já em 1999 e, na sequência, alterar os procedimentos de elaboração e execução do orçamento para que ele pudesse ser subordinado à política macroeconômica, no intuito também de recuperar a credibilidade desta.

O acordo com o FMI consagrou a decisão de construir um novo regime fiscal, explicitando a necessidade de adoção de regras fiscais e o princípio da sustentabilidade da dívida como elementos norteadores da política fiscal que, juntamente com a defesa da credibilidade das autoridades fiscais, refletiam as ideias do NCM, consistentes com a lógica teórica do plano de estabilização.

\section{A POLÍTICA FISCAL NO NOVO REGIME DE POLÍTICA MACROECONÔMICA}

O novo regime fiscal se sacramentou dentro de um novo regime de política macroeconômica, consolidado após a crise de 1999. Do lado cambial, não suportando as pressões especulativas contra a moeda e a despeito da recorrência aos recursos do FMI e das negociações junto à comunidade financeira internacional, o País deixa o regime de taxas administradas em janeiro de 1999 e passa a adotar o câmbio flexível, com taxas determinadas pelo mercado ${ }^{23}$. Do lado monetário, a instituição das metas de inflação daria as novas bases para o trato da política: o Conselho Monetário Nacional passava a determinar as metas a serem atingidas a cada ano e o BC a controlar a taxa SELIC que se julga compatível com a inflação na meta definida. Fechava-se, portanto, o modelo de política macroeconômica proposto pelo NCM, com a taxa de juros como variável

${ }^{21}$ Enquanto no primeiro ponto estavam discussões como a da reforma do RGPS, o avanço institucionallegal inspirava o que se transformou posteriormente na Lei de Responsabilidade Fiscal (LRF) e, por fim, a estabilização da dívida pautava-se na determinação de geração dos superavit primários para os anos de 1999 a 2001.

${ }^{22}$ Mesmo estabelecendo o corte de gastos públicos, o PEF dava maior ênfase na arrecadação e tinha como principais medidas os aumentos das alíquotas das contribuições sociais (CPMF e COFINS), dos "percentuais de contribuição para o plano de aposentadoria do servidor público e criação da contribuição para os inativos" (FILGUEIRAS, 2000, p. 140).

${ }^{23}$ A rigor, o Brasil utilizava um regime de "bandas cambiais" e passou ao de "flutuação suja" após a crise de 1999. No primeiro caso, o BC permitia uma variação estreita do câmbio, em torno de $1 \%$, para que este atuasse como âncora dos preços e das expectativas inflacionárias. Já na "flutuação suja", modelo adotado de 1999 até os dias de hoje, o câmbio flutua, mas o BC atua no mercado quando há valorização ou desvalorização excessiva do Real. Em outros termos, o BC controla a liquidez interna, comprando ou vendendo dólares por meio de mecanismos como a oferta de títulos da dívida pública indexados ao câmbio ou por meio dos swaps cambiais. Ver Prates (2010). 
de ajuste macroeconômico para a obtenção da estabilidade de preços no longo prazo (as metas de inflação). Com a política fiscal comprometida com as metas de superavit primário compatíveis com a estabilidade da relação dívida/PIB, completava-se a nova concepção de política macroeconômica, conhecida desde então como o "tripé macroeconômico" (câmbio flexível, metas de inflação e superavit primário).

Nesse novo regime macroeconômico, orientado pela política monetária e que faz jus às proposições do NCM, a política fiscal deixa de ter papel ativo na gestão da demanda agregada e se torna central como sua base de sustentação. É por meio dela que os fundamentos (fundamentals) da economia são mantidos para que a atuação da política monetária seja eficiente. As medidas de política fiscal devem responder sempre às expectativas de risco dos agentes e às previsões sobre o comportamento futuro das variáveis com influência direta na relação dívida/PIB, garantindo, portanto, sua sustentabilidade e o espaço para a valorização do capital privado (LOPREATO, 2006a).

Já no início da mudança do regime macroeconômico a política fiscal teve de se valer desse papel a ela atribuído. A despeito da melhora nas contas externas, a brusca e excessiva desvalorização ${ }^{24}$ do Real nos meses seguintes à mudança do regime cambial pressionou a inflação e comprometeu a dívida pública. Para conter a inflação, numa atitude condizente com o regime de metas, o BC aumentou significativamente a taxa de juros, que passou de $15 \%$ a.a. em setembro de 1998 e atingiu $42 \%$ a.a. em março de 1999. A dívida pública, por seu turno, absorveu o duplo impacto: o da desvalorização sobre a parcela da dívida indexada ao câmbio e o da elevação dos juros. O resultado foi o salto para 48,7\% da relação dívida/PIB no ano de 1999 (Tabela 3). Assim, as consequências negativas da desvalorização cambial impuseram de fato a necessidade do aprofundamento no esforço fiscal para aliviar seu impacto sobre a dívida e sobre as expectativas dos agentes.

Tabela 3 - Dívida líquida do setor público, 1999-2002 (em \% PIB)

\begin{tabular}{lcccc}
\hline & $\mathbf{1 9 9 9}$ & $\mathbf{2 0 0 0}$ & $\mathbf{2 0 0 1}$ & $\mathbf{2 0 0 2}$ \\
\hline Gov. Federal e Bacen & 29,8 & 30,6 & 31,3 & 37,7 \\
Gov. Estaduais e Municipais & 16,1 & 16,1 & 17,5 & 19,7 \\
Empresas Estatais & 2,8 & 2,2 & 2,7 & 2,6 \\
Dívida Total & $\mathbf{4 8 , 7}$ & $\mathbf{4 8 , 9}$ & $\mathbf{5 1 , 5}$ & $\mathbf{5 9 , 9}$ \\
\hline
\end{tabular}

Fonte: Elaboração própria com base em dados de BACEN.

${ }^{24}$ O câmbio atingiu R\$1,80/US\$ logo após a desvalorização de 1999, representando uma desvalorização real de cerca de $50 \%$. 
A estratégia da política macroeconômica de estabilidade sistêmica dependia sobremaneira da política fiscal nesse contexto. Além de conter a expansão da demanda agregada para viabilizar as metas de inflação, ela deveria manter o compromisso com a redução da dívida pública, evitando que os agentes revisassem suas expectativas com relação às contas públicas, que essas revisões provocassem turbulências no mercado de câmbio e que surgissem surtos inflacionários decorrentes dos mecanismos de transmissão das desvalorizações cambiais aos preços (LOPREATO, 2006b).

Com a piora da dívida, sob as orientações do PEF e pelas determinações da Lei de Diretrizes Orçamentárias (LDO), as metas do superavit primário foram estabelecidas em 3,1\% do PIB em 1999, 3,25\% em 2000 e 3,5\% em 2001. Segundo as estimativas do governo, essa trajetória dos superavit seria adequada para a estabilização da dívida em $46 \%$ do PIB.

Tabela 4 - Necessidades de financiamento do setor público, 1999-2002 (em \% PIB)

\begin{tabular}{lcccc}
\hline & $\mathbf{1 9 9 9}$ & $\mathbf{2 0 0 0}$ & $\mathbf{2 0 0 1}$ & $\mathbf{2 0 0 2}$ \\
\hline Nominal & 5,82 & 3,61 & 3,45 & 4,45 \\
Juros Nominais & 9,05 & 7,08 & 6,67 & 7,66 \\
Primário & $\mathbf{- 3 , 2 3}$ & $\mathbf{- 3 , 4 6}$ & $\mathbf{- 3 , 2 1}$ & $\mathbf{- 3 , 2 2}$ \\
\hline
\end{tabular}

Fonte: Elaboração própria com base em dados de BACEN.

O superavit primário de 3,23\% em 1999 (acima da meta, portanto) e a inflação de $8,9 \%$ (dentro do limite de variação estabelecido) mostraram o sucesso parcial do novo regime. O cumprimento das metas de superavit também no período de 2000 a $2002^{25}$ consolidou a política fiscal como pilar macroeconômico e foi relevante na recuperação momentânea da credibilidade da política econômica do governo, apesar de não lograr reduzir a relação dívida/PIB, uma vez que o esforço fiscal foi mais que compensado pela pressão dos juros e do câmbio.

A fragilidade do balanço de pagamentos à época e os ataques especulativos contra o câmbio provocaram a desvalorização do Real e forçaram o aumento dos juros com o objetivo de evitar a fuga de capitais e conter a propagação inflacionária, com implicações

25 A meta de superavit primário para o ano de 2002 era inicialmente de 3,75\% do PIB e, após discussão com membros do FMI em setembro de 2002, passou para 3,88\% do PIB. Dados de 2006, presentes em Santos (2007) mostram que o superavit primário foi superior às metas de 2001 e 2002, quando apresentou 3,64\% e 3,89\% do PIB respectivamente. Para análise da conjuntura do momento, em 2007, estes eram os dados relevantes. Como as contas públicas passam por constantes revisões, de apuração e de metodologia, como a do PIB de 2007, por exemplo, os resultados se alteraram, de maneira que a Tabela 4 apresenta os dados revisados. 
diretas sobre o estoque da dívida pública. A crise internacional de 2001 e a tensão do processo eleitoral de 2002 acentuaram os problemas de câmbio e de juros e colocaram a política fiscal à prova, diante da continuidade do processo de elevação da dívida pública. O salto para o patamar de 62,5\% do PIB em setembro de 2002 realçou o risco de default e passou a requerer nova rodada de ampliação do superavit primário.

O ganho momentâneo de credibilidade da política econômica veio acompanhado de baixo crescimento do PIB $^{26}$, que voltou ao nível observado no período de alta inflação e de expressivo ônus social, representado pelo aumento significativo da carga tributária, que se elevou de 29,7\% do PIB em 1999 para 35,9\% em 2002. Dessa forma, a questão tributária passou a ser outro ponto fundamental da discussão no âmbito fiscal para os anos posteriores ao mandato FHC.

O novo regime de política fiscal consolidou-se, como parte do modelo maior de condução da política macroeconômica determinada pelo tripé. A obtenção sistemática de superavit primários passou a ser a condição necessária para manter o principal indicador das finanças públicas num patamar estável (e de preferência em queda) desde então. O uso da política fiscal com essa finalidade, contudo, não eliminou a instabilidade macroeconômica, inerente à própria forma como a estratégia foi montada, nem garantiu a retomada do crescimento. A volatilidade das expectativas dos agentes e a instabilidade das variáveis câmbio e juros aprisionaram a política na defesa da sustentabilidade da dívida. Desde então, o ajuste fiscal, ou seja, a variação nos superavit primários, passou a ser feito sempre em respostas às mudanças dessas variáveis e deixou a estratégia refém das expectativas do mercado.

Essa configuração mostrou-se condizente com a opção de desenvolvimento adotada pelo governo, cerca de uma década antes, de inserir o País na dinâmica internacional, promover aberturas financeira e comercial e integrar o circuito internacional de valorização do capital. A opção resultou em um modelo de condução de política fiscal que deveria criar as condições para uma boa avaliação do mercado a respeito da economia brasileira e, simultaneamente, agir em resposta à instabilidade provocada pelo próprio movimento do mercado. No final do governo FHC, essa instabilidade fica patente, dadas a crise internacional de 2001 e a instabilidade interna provocada pela incerteza com relação ao resultado das eleições de 2002. Mesmo sem obter estabilidade macroeconômica, é inegável que o regime fiscal havia se modificado significativamente. O País entrava nos anos 2000 com uma nova lógica de condução da política fiscal, com implicações sobre a estrutura do Estado, as relações federativas e a definição de regras fiscais e de controle do endividamento.

\footnotetext{
${ }^{26}$ A taxa de crescimento real média do PIB entre 1999 e 2002 foi de 2,3\% a.a., mesmo patamar do período de 1980 a 1993, de 2,2\% (cf. ORAIR, 2016 e IPEADATA).
} 


\section{O PRIMEIRO GOVERNO LULA E O APROFUNDAMENTO DO REGIME FISCAL}

As crises de 2001 e 2002 explicitaram a fragilidade da política macroeconômica, ancorada no ajuste da taxa de juros, em garantir a estabilidade sistêmica nos moldes do modelo do NCM. Entretanto, ao invés de levarem à mudança de estratégia macroeconômica, serviram para aprofundá-la e reafirmar o papel subordinado da política fiscal, a fim de dar condições para a política monetária atuar, bem como reagir aos efeitos negativos de câmbio e juros sobre as contas públicas.

O cenário em que Lula assumiu a presidência em 2003 era de instabilidade interna, trazida com as turbulências pré-eleitorais, e de vulnerabilidade externa, oriunda da reversão do ciclo de liquidez internacional a partir de 2001. O principal indicador fiscal havia fechado o ano anterior com o maior nível de fim de período já atingido até então (Tabela 5). Fortemente influenciada pela desvalorização cambial, que nos momentos de maior tensão havia se aproximado de R $4 / \mathrm{US} \$$, a relação dívida/PIB encerrou 2002 em 59,9\% ${ }^{27}$ e a inflação, medida pelo IPCA, índice usado para o cálculo das metas, havia chegado a $12,5 \%$, ultrapassando em muito o limite do intervalo de tolerância de 2 p.p. acima do centro da meta estabelecida para o ano, de 3,5\%. Esses resultados atestaram que a proposta de gestão na política fiscal no governo FHC cumpriu-se em parte, pois, a despeito dos avanços na reorganização fiscal e da gestão pública, não conseguiu eliminar o deficit público. Mantido o compromisso com a opção de política econômica implementada a partir de 1999, o governo que se iniciaria em 2003 teria que enfrentar uma situação adversa.

O primeiro passo da política do governo Lula foi estabelecer o que Barbosa e Souza (2010) chamam de um ajuste macroeconômico sólido e necessário para a retomada do controle da situação monetária, fiscal e cambial do País. No campo monetário, para conter a inflação e garantir a estabilidade do câmbio, que sofria ataques especulativos, o $\mathrm{BC}$ voltou à política de aumentar a taxa básica de juros, que chegou a 26,5\% (entre fevereiro e julho de 2003) e fechou o ano em 16,5\%. No campo fiscal, a demonstração de comprometimento com o ajuste ficou por conta do aumento das metas de superavit primário de 3,75\% para 4,25\% do PIB para o quadriênio de 2003-2006, no intuito de afastar a preocupação do mercado com a possibilidade de aumento explosivo da dívida pública.

${ }^{27}$ Aproximadamente 2,6 pontos percentuais (p.p.) do PIB abaixo do pico atingido em setembro, de $62,5 \%$. 
Tabela 5 - Indicadores de desempenho fiscal, Brasil (em \% PIB)

\begin{tabular}{lcccc}
\hline Ano & Pagamento de Juros & Resultado Nominal & Superavit Primário & Dívida/PIB \\
\hline $\mathbf{2 0 0 1}$ & 6,6 & $-3,4$ & 3,2 & 51,5 \\
$\mathbf{2 0 0 2}$ & 7,6 & $-4,4$ & 3,2 & 59,9 \\
$\mathbf{2 0 0 3}$ & 8,4 & $-5,2$ & 3,3 & 54,3 \\
$\mathbf{2 0 0 4}$ & 6,6 & $-2,9$ & 3,7 & 50,2 \\
$\mathbf{2 0 0 5}$ & 7,3 & $-3,5$ & 3,8 & 47,9 \\
$\mathbf{2 0 0 6}$ & 6,8 & $-3,6$ & 3,2 & 46,5 \\
\hline
\end{tabular}

Fonte: Elaboração própria com base em dados de BACEN.

Em 2003, o maior esforço fiscal como participação do PIB, aliado à apreciação cambial real de $18 \%$, fez com que a relação dívida/PIB se reduzisse a 54,3\% em dezembro. Uma redução mais significativa não ocorreu devido ao maior custo financeiro que incidiu sobre a dívida, em decorrência da política monetária austera praticada em 2003. A alta taxa de juros, a despeito de conseguir segurar a inflação ${ }^{28}$, ancorada na valorização cambial, implicou em maior pagamento de juros - 8,4\% do PIB em 2003 - e se somou ao inexpressivo crescimento da economia em 2003, de 1,1\%. Outro agravante é que o arrocho fiscal recaiu sobre os investimentos da União, que se reduziram de 1,1\% do PIB em 2002 para 0,3\% em 2003, e sobre o salário mínimo, que teve um aumento real de apenas $0,7 \%$ em $2003^{29}$ (BARBOSA e SOUZA, 2010).

Diante da conjuntura, o governo Lula aprofundou o comportamento de acordo com o ideário ortodoxo, recorrendo à "contração fiscal expansionista” (GIAVAZZI e PAGANO, 1990). Segundo essa hipótese, a contração fiscal não provoca necessariamente recessão, nem mesmo no curto prazo, pois as ações do governo podem criar ambiente favorável à atuação privada, levando, ao contrário, à expansão econômica. Com base nessa visão, a partir de 2003 o governo orientou as ações fiscais em defesa da redução da dívida/PIB, pois acreditava que, aliada ao cumprimento das regras fiscais, trouxesse confiança do mercado à política macroeconômica e, assim, abrisse espaço ao crescimento.

O Ministro da Fazenda à época, Antonio Palocci, manteve a postura do governo anterior: aprofundou a política de geração de superavit primários e criou um plano de ajuste fiscal de longo prazo, para zerar o deficit nominal e incentivar o crescimento $^{30}$.

${ }^{28}$ Que fechou o ano em 9,3\%, pouco acima do limite de tolerância de 8,5\%.

29 De acordo com Lopreato (2013, p. 202): "Ao final do mandato de FHC, a situação fiscal, apesar do aumento da carga tributária e do elevado superavit primário, era motivo de preocupação, já que o baixo crescimento e a instabilidade dos juros e do câmbio comprometiam o comportamento da dívida pública e impunham restrições à retomada dos investimentos do setor público".

30 A esse respeito ver também Brasil (2003). 
O diagnóstico do governo era de que a "menor necessidade de financiamento, a ser alcançada com o ajuste fiscal, reduziria o prêmio de risco dos títulos públicos e a taxa de juros, com reflexos sobre a disponibilidade de recursos públicos e os investimentos do setor privado" (LOPREATO, 2013, p. 206).

A recuperação econômica de 2004 e a melhora dos indicadores fiscais deram certo respaldo à estratégia da "contração fiscal expansionista" tomada como norteadora das ações do Ministério da Fazenda. A apreciação cambial iniciada em 2003, a redução da inflação e da taxa de juros básica, e o crescimento das exportações (a despeito do câmbio apreciado) foram fatores importantes na retomada do crescimento da economia entre 2004 e $2005^{31}$ (BARBOSA e SOUZA, 2010). Já a minirreforma tributária de 2004, com as mudanças na tributação do PIS/COFINS sobre as empresas trouxeram, em conjunto com a expansão do PIB, aumento da arrecadação pública, usado para elevar o resultado primário e reduzir o indicador dívida/PIB.

Tabela 6 - Dívida líquida do setor público (em \% PIB)

\begin{tabular}{lcccccc}
\hline & $\mathbf{2 0 0 1}$ & $\mathbf{2 0 0 2}$ & $\mathbf{2 0 0 3}$ & $\mathbf{2 0 0 4}$ & $\mathbf{2 0 0 5}$ & $\mathbf{2 0 0 6}$ \\
\hline Dívida Líquida Total & 51,5 & 59,9 & 54,3 & 50,2 & 47,9 & 46,5 \\
Dívida Interna líquida & 42,0 & 44,4 & 43,2 & 42,4 & 44,8 & 47,6 \\
Dívida Externa Líquida & 9,5 & 15,6 & 11,0 & 7,8 & 3,1 & $-1,2$ \\
\hline
\end{tabular}

Fonte: Elaboração própria com base em dados de BACEN.

Com a evolução do favorável PIB e a redução da dívida, a "contração fiscal expansionista" ganhou força e logo se apresentaram os chamados a favor de maior ímpeto no ajuste fiscal. A defesa da austeridade passava pela geração de superavit progressivos até a eliminação do deficit nominal do setor público que, segundo o argumento de Delfim Netto (2005), conseguiria não apenas provocar queda significativa da relação dívida/ PIB, como também reduzir a estrutura a termo das taxas de juros, com reflexo na conta de juros do País.

O objetivo do nominal zero num horizonte bem definido, com o congelamento das despesas em lugar do aumento dos impostos, criará instantaneamente uma expectativa de baixa do juro real, que facilitará à Secretaria do Tesouro a substituição de parte da dívida "selicada" para papéis pré-fixados (com prazos maiores), aumentando a potência da política monetária. (DELFIM NETTO, 2005, p. 9)

${ }^{31}$ O PIB cresceu 5,8\% e 3,2\% em 2004 e 2005, respectivamente (ORAIR, 2016). 
Além da proposta de aumento significativo do superavit primário, a ponto de eliminar o deficit nominal, também se colocavam, de acordo com Tavares (2005), a necessidade de avançar as questões das reformas estruturais, presentes desde as propostas do PAI. Giambiagi (2005) e Velloso (2006) seguem a mesma linha e propõem medidas na área tributária e de gestão dos gastos públicos. São temas recorrentes na análise dos dois autores a questão previdenciária, com a definição de regras mais rígidas para alcançar os benefícios; a redução dos gastos não financeiros do setor público, principalmente da União, para elevar o superavit primário e o compromisso com os encargos financeiros; uma reforma tributária que, além de atingir eficiência na arrecadação, dispense o recurso das contribuições, de modo a expandir a receita sem contrapartida de gasto preestabelecido; a desvinculação das receitas das contribuições já existentes; redução dos gastos correntes do Estado com a máquina pública, com o enxugamento do quadro de pessoal; a focalização das políticas públicas, a fim de reduzir o escopo de programas sociais e de garantia de renda, entre outras. No limite, são reformas estruturais que, de acordo com essa visão, ao reduzirem a participação do Estado, garantem o equilíbrio orçamentário de longo prazo e colocam o País no caminho do aumento dos investimentos, crescimento econômico e redução das mazelas sociais.

A opção pela "contração fiscal expansionista”, concentrada na austeridade fiscal e na solvência da dívida, abria pouco espaço às ações do Estado, principalmente no que cabe à articulação dos investimentos e à indução do crescimento. $\mathrm{O}$ papel do Estado restringia-se àquele proposto pelo NCM, de garantir a estabilidade sistêmica por meio do comprometimento com regras predefinidas e de fornecer aos agentes um ambiente estável para a tomada de decisões. Como Barbosa e Souza (2010, p. 8) afirmam, "nos três anos iniciais do governo Lula, a visão neoliberal foi predominante nas ações de política econômica”, mas, como o ajuste fiscal entre 2003 e 2005 não havia acelerado substancialmente o crescimento e, tampouco, havia ajudado na melhora substantiva do emprego e renda ${ }^{32}$, a estratégia esgotou-se e deu espaço às visões desenvolvimentistas, também presentes no interior do governo. A partir de 2006 ficam claras as opções de política segundo essa orientação.

\footnotetext{
32 A média de crescimento do PIB foi de 3,4\% a.a. entre 2003 e 2005, pouco acima dos dois governos anteriores, mas abaixo da média alcançada no período seguinte, de mudança da atuação fiscal, como veremos na sequência. O número total de empregados com vínculo formal teve aumento pouco expressivo, passando de 29,5 milhões em 2003 para 33,2 milhões em 2005 e a massa salarial real cresceu 1,2\% a. a. no período (GOMES e CRUZ, 2017).
} 


\section{SEGUNDO GOVERNO LULA ${ }^{33}$ E AS MUDANÇAS NA CONDUÇÃO DA POLÍTICA FISCAL}

As propostas de aprofundamento do regime fiscal acirraram o debate dentro do próprio governo e a queda de Palocci representou o marco da mudança para a implementação de políticas de caráter desenvolvimentista. Essa visão não refletia uma escola de pensamento hegemônica, mas, contrapondo à visão neoliberal, conseguiu colocar propostas pragmáticas e relativamente coesas, baseadas principalmente (i) nos estímulos fiscais e monetários para acelerar o crescimento e aumentar o produto potencial da economia, (ii) nas transferências de renda e aumento real do salário mínimo para acelerar o desenvolvimento e (iii) no aumento do investimento público e da participação do Estado no planejamento de longo prazo. Apesar de boa parte das medidas coincidirem com o período da crise econômica mundial de 2008, as linhas de ação do Estado já estão dadas desde 2006 e não podem ser atribuídas a mero pragmatismo no enfrentamento da crise. A situação internacional reforçou a trajetória adotada e serviu de justificativa para a retirada de restrições ainda existentes e a continuidade da estratégia.

No caso dos incentivos e subsídios fiscais, com auge em 2009, a estratégia pautou-se basicamente em reduções tributárias de setores com alta articulação para frente e para trás na cadeia produtiva, em subvenções econômicas no âmbito do Plano de Sustentação do Investimento (PSI), além da ampliação do crédito por meio das ações dos bancos públicos (Caixa Econômica Federal, Banco do Brasil e BNDES). As desonerações tornaram-se parte da política industrial tanto na Política de Desenvolvimento Produtivo (PDP), de fomento ao setor industrial, quanto no PSI e se materializaram em medidas como as de: aproveitamento rápido de créditos tributários para investimento, depreciação acelerada dos investimentos, redução de tributos (IPI, PIS-PASEP, COFINS, IR, IOF) para aumento do investimento e das exportações, e equalização das taxas de juros. Destaca-se também a reconstituição do mecanismo de preferência pelas compras públicas, em que se estabeleceu uma margem (de até $25 \%$ acima do preço dos produtos estrangeiros) para o favorecimento na compra de produtos manufaturados e serviços nacionais e/ou de empresas que investissem em P\&D no país. Este instrumento, aliado à proposta de conteúdo nacional, generalizado a partir do marco legal da exploração do pré-sal, buscava incentivar a produção nacional e o aumento da nacionalização das compras públicas, por meio da intervenção do Estado, voltado para elevar o seu poder de atuação no esforço de adensamento das cadeias produtivas e de indução à pesquisa e inovação no país. O investimento total no país, medido pela formação bruta de capital fixo, saiu de 15,8\% do PIB em 2003 e "aproximou-se de 20\% do PIB em 2008,

${ }^{33}$ Cronologicamente, o segundo mandado do presidente Lula se iniciou em janeiro de 2007. Para fins de representação da mudança da política econômica adotada, estamos consideramos o ano de 2006. 
patamar não conhecido pela economia brasileira desde os anos de 1970" (LOPREATO e DEDECCA, 2013, p. 4) e, após pequena queda em 2009 devido à crise mundial, fechou 2010 em 20,2\% do PIB.

Além desses incentivos, a segunda fase do governo Lula buscou gerar um círculo virtuoso a partir da atuação federal na redução das desigualdades sociais e na distribuição de renda (BARBOSA e SOUZA, 2010). A partir de 2006, intensificou-se o processo de transferência de renda como instrumento de desenvolvimento social e econômico e os estímulos ao consumo como fonte de crescimento da demanda agregada ${ }^{34}$. A lógica era a de que o aumento das transferências poderia ocorrer sem contraparte de desequilíbrios fiscais, uma vez que se autofinanciariam por meio do crescimento econômico e da arrecadação. O resultado esperado era o crescimento com a redução das desigualdades sociais, ao mesmo tempo em que se alcançava a estabilidade das contas públicas.

Os instrumentos de sustentação da proposta foram a política deliberada de crescimento real do salário mínimo e dos gastos sociais, com destaque para o Bolsa Família. A política do salário mínimo teve o intuito de recompor as perdas salariais do período de alta inflação e o poder de barganha dos trabalhadores, principalmente do setor de serviços e da economia informal (BARBOSA e SOUZA, 2010). A média de crescimento real do salário mínimo passou de 11,7\% entre 2003-2005 para 24,7\% entre 2006$2008^{35}$. A ampliação do Bolsa Família, por seu turno, expressava o compromisso do governo com as políticas de transferências de renda e de inclusão social, base da proposta que o elegera. Nesse caso, houve aumento sistemático dos recursos destinados ao programa ao longo do período, passando de 0,1\% do PIB em 2003 para 0,4\% em 2008. Além, disso, como Baltar et al. (2017) afirmam, o crescimento com inclusão social também se caracterizou pela elevada criação de emprego formal no período, que chegou a 44,1 milhões de vínculos em 2010, ano com a maior geração líquida de postos de trabalho (2,6 milhões) desde a estabilização econômica (GOMES e CRUZ, 2017).

O aumento real do salário mínimo e das transferências de renda, aliados à expansão do crédito e ao quadro internacional favorável até a crise, acabaram por evidenciar as possibilidades de crescimento baseado no mercado doméstico e na expansão da demanda agregada, em simultâneo com a redução consistente das desigualdades sociais ${ }^{36}$.

${ }^{34} \mathrm{O}$ consumo total cresceu a média de 5,2\% ao ano entre 2006 e 2010, contra a média de 2,5\% de 2003 a 2005 (LOPREATO e DEDECCA, 2013).

35 Na mesma linha de argumentação, Baltar et al. (2017) afirmam que junto ao aumento real do salário mínimo, as negociações de classes ajudaram no aumento do poder de compra da renda do trabalho em $34,7 \%$ de 2003 a 2008 e $23,9 \%$ entre 2008 e 2013.

${ }^{36}$ O índice Gini caiu de 0,587 em 2002 para 0,533 em 2011 (dados de 2010 não publicados) (GOMES e CRUZ, 2017). 
A expansão do consumo veio acompanhada do aumento do investimento público e da participação do Estado na economia, por meio dos programas governamentais de grande vulto e do papel dos bancos públicos e das empresas estatais. As ações, capitaneadas pela articulação entre o Ministério da Fazenda e o BNDES, buscavam remontar a capacidade de atuação dos mecanismos fiscais e financeiros de sustentação do investimento e de apoio às atividades privadas.

Os programas do PAC e o Minha Casa Minha Vida foram importantes na retomada da articulação entre o setor público e o capital privado, por conta do apoio via crédito público e os instrumentos fiscais, buscando expandir gastos em infraestrutura e programas sociais. A PDP, por seu turno, representou uma ação sistêmica no campo industrial maior do que a política anterior (Política Industrial, Tecnológica e de Comércio Exterior), no intuito de reforçar a interação entre as instituições públicas e o setor privado e impulsionar a competitividade em vários setores, embora não tenha alcançado os resultados esperados para o setor industrial ${ }^{37}$. A articulação entre os interesses públicos e privados, promovida pelo Estado com o uso de incentivos fiscais e financiamento do BNDES, se deu basicamente por meio de três eixos de atuação: a criação de grupos com participação pública e privada, para investir em infraestrutura; o incentivo às fusões e incorporações, para a concentração setorial e para o ganho de competitividade no mercado internacional; e o patrocínio da internacionalização das empresas nacionais. Com essas ações, incorporava-se na política industrial a tese da atuação global dos grupos nacionais para aumentar a competitividade internacional e gerar empregos e inovações no mercado interno, refletindo positivamente na economia como um todo ${ }^{38}$.

Os bancos públicos funcionaram, primeiramente, de maneira anticíclica, ao fornecerem o crédito necessário no momento de tensão do mercado financeiro (privado) por conta da crise global. A política de equalização das taxas de juros nas operações de financiamento de investimento (PIS-BNDES) e as linhas de crédito de capital de giro atenuaram a crise e impulsionaram a recuperação econômica. Com a finalidade de evitar os riscos de crise bancária, o Banco do Brasil e a Caixa Econômica Federal adquiriram participação em instituições financeiras e ampliaram a presença no mercado bancário brasileiro, de modo a reafirmar o papel dos bancos públicos como agentes financiadores do longo prazo e propulsores do crescimento.

\footnotetext{
37 A valorização cambial e o avanço da China foram fatores que, certamente, contribuíram para as dificuldades vividas pelo setor industrial.

38 Para uma análise aprofundada das transformações produtivas, desenvolvimento industrial no Brasil e internacionalização das empresas brasileiras ver Hiratuka e Sarti $(2011,2017)$.
} 
A estratégia oficial buscou ainda fortalecer a capacidade financeira e o poder de ação das empresas estatais. A Eletrobras, a Valec-Engenharia e a Petrobras, tiveram aumento do capital viabilizado via Tesouro Nacional ${ }^{39}$, a fim de cumprirem a tarefa de coordenar as ações em áreas prioritárias, catalisar novos investimentos e fomentar o gasto privado. A Eletrobras assumiu parcela relevante dos projetos do PAC e se beneficiou com o aumento de sua participação nos projetos hidroelétricos, nos investimentos em energia nuclear e nas linhas de transmissão. A Valec elevou o capital social e o quadro de pessoal, além de retomar, desde 2009, a construção da ferrovia Norte-Sul, bem como manteve sob sua responsabilidade os projetos de construção e de concessões previstos no $\mathrm{PAC}^{40}$. Por fim, a Petrobras é o principal exemplo da mudança de postura do governo com relação às suas estatais. Entre 2007 e 2008, a empresa teve aumento significativo de capital e ocorreu a mudança do marco regulatório, ambos possibilitados pela descoberta do pré-sal. A adoção do sistema de partilha deu à União maior controle e parcela do óleo explorado e a Petrobras tornou-se a operadora única nessa atividade, com participação de $30 \%$ em todos os blocos. Essas e outras medidas ${ }^{41}$ demonstraram a aposta do governo no poder da empresa e do setor em elevar os gastos e liderar a retomada do crescimento.

O resultado foi o crescimento dos investimentos públicos em 17\% a.a. em termos reais entre 2006 e 2010, capitaneados pela atuação das empresas estatais federais, cujos investimentos aumentaram em $130,5 \%$ no período ${ }^{42}$. A retomada dos investimentos, aliada à maior oferta do crédito e ao aumento do consumo, graças aos mecanismos de distribuição de renda, responsáveis por incorporar parcela significativa da população ao mercado de massa, contribuíram para a expansão do PIB. O ritmo de crescimento, apesar de se manter abaixo do patamar observado nos países em desenvolvimento, atingiu a 4,6\% a.a., maior média desde o Plano Real.

A maior presença do Estado e as ações de caráter desenvolvimentista alteraram em parte o cânone macroeconômico, pois, mesmo mantendo o tripé, as medidas no campo fiscal se destinaram ao controle da demanda agregada e ao fomento do crescimento econômico ${ }^{43}$.

39 Ver Lopreato (2013, cap. 5) para discussão mais aprofundada.

40 As alterações previstas no novo marco regulatório do setor ferroviário, como a possibilidade de comercializar trechos de concessionárias privadas ainda não explorados, também cria condições para a Valec intervir no manejo da malha ferroviária e aumentar a atuação do Estado no transporte de grandes cargas.

${ }^{41}$ Como a cessão onerosa à Petrobras, sem licitação, da prospecção de petróleo e gás em áreas ainda não concedidas, o pagamento por meio de títulos da dívida pública mobiliária federal, a subscrição de ações do capital social da Petrobras, além da criação da Pré-Sal Petróleo SA.

42 De acordo com Orair (2016), o volume de investimentos das estatais federais em 2010 era da ordem de R\$ 105,1 bilhões contra R\$ 45,6 bilhões, a preços de 2015. Os investimentos do governo central (Tesouro Nacional, INSS e BC) apresentaram a maior taxa de crescimento anual (25,3\% ao ano), porém com um volume de recursos representando em média, $40 \%$ dos investimentos das estatais.

${ }^{43}$ Retomando, em certa medida, o pensamento da vertente pós-keynesiana que defende que a política fiscal tem, pelo menos, o mesmo peso que a política monetária no controle macroeconômico (ARESTIS e SAWYER, 2003c; FONTANA, 2009b; TCHERNEVA, 2008). 
A mais clara expressão da nova forma de enxergar o papel da política fiscal no desenho da política macroeconômica veio por meio das ações da estabilização da relação dívida/PIB e da dinâmica de geração dos superavit primários. As metas de superavit primário passaram por constantes revisões, principalmente no que cabe aos descontos da parcela de investimento público do seu cálculo ${ }^{44,45}$, na tentativa de acelerar o crescimento. Certamente, o foco se voltou ao denominador da relação dívida/PIB. A despeito das críticas à política de redução do esforço primário, a estratégia não rompeu com os elementos centrais do regime fiscal do governo anterior e tampouco houve descuido com o resultado fiscal. Pelo contrário, as contas públicas apresentaram bom desempenho. O deficit nominal, depois de crescer a 3,2\% do PIB em 2009 (ano agudo da crise mundial) voltou a se reduzir para 2,4\% em 2010, índice baixo quando comparado à situação internacional. A relação dívida/PIB caiu de maneira sistemática e o aumento verificado em 2009 logo foi revertido, fazendo a relação voltar ao patamar de 2008, graças, em boa medida, ao efeito do crescimento do PIB sobre a dívida (Tabela 7).

Tabela 7 - Evolução da dívida líquida do setor público, consolidado (em \% PIB)

\begin{tabular}{lccccc}
\hline & $\mathbf{2 0 0 6}$ & $\mathbf{2 0 0 7}$ & $\mathbf{2 0 0 8}$ & $\mathbf{2 0 0 9}$ & $\mathbf{2 0 1 0}$ \\
\hline Dívida líquida total - saldo & $\mathbf{4 6 , 5}$ & $\mathbf{4 4 , 6}$ & $\mathbf{3 7 , 6}$ & $\mathbf{4 0 , 9}$ & $\mathbf{3 8}$ \\
Dívida líquida - var. ac. ano & $-\mathbf{1 , 4}$ & $\mathbf{- 1 , 9}$ & $-\mathbf{7}$ & $\mathbf{3 , 4}$ & $\mathbf{- 3}$ \\
Fatores condicionantes & $\mathbf{3 , 3}$ & $\mathbf{3 , 4}$ & $\mathbf{- 1 , 4}$ & $\mathbf{5 , 8}$ & $\mathbf{2 , 9}$ \\
NFSP & 3,6 & 2,7 & 2 & 3,2 & 2,4 \\
Primário & $-3,2$ & $-3,2$ & $-3,3$ & $-1,9$ & $-2,6$ \\
Juros nominais & 6,7 & 6 & 5,3 & 5,1 & 5 \\
Ajuste cambial & $-0,3$ & 0,8 & $-2,5$ & 2,4 & 0,5 \\
Dívida externa - outros ajustes & 0,1 & $-0,1$ & $-0,8$ & 0,3 & 0 \\
Reconhecimento de dívidas & 0 & 0 & 0 & 0 & 0,1 \\
Privatizações & $-0,1$ & 0 & 0 & $-0,1$ & $-0,1$ \\
Efeito do crescimento do PIB sobre a dívida & $-\mathbf{4 , 7}$ & $\mathbf{- 5 , 3}$ & $\mathbf{- 5 , 6}$ & $\mathbf{- 2 , 5}$ & $\mathbf{- 5 , 9}$ \\
\hline
\end{tabular}

Fonte: Elaboração própria com base em dados de BACEN.

${ }^{44}$ A primeira medida neste sentido foi a exclusão da contabilização dos gastos primários os investimentos do Plano Piloto de Investimentos em 2005, sendo 2006 o primeiro ano em que esse artifício contábil foi utilizado. A exclusão dos investimentos do PAC consolidou essa estratégia nos anos seguintes, que se ampliou em 2009, ao deixar de contabilizar os investimentos da Petrobras e da Eletrobras.

45 “... a proposta desenvolvimentista era adaptar as metas fiscais à importância do investimento público e ao peso do pagamento de juros sobre o orçamento público, retirando os investimentos mais estratégicos do cálculo do resultado primário do governo federal” (BARBOSA, 2010, p. 13). 
Enfim, pode-se afirmar que os fatores determinantes do sucesso da trajetória econômica do governo Lula, sobretudo pós-2006, não estão na manutenção do tripé convencional da política macroeconômica, mas sim nas mudanças da forma de atuação da política fiscal e do papel do Estado, presentes na política de aumento real do salário mínimo e na expansão dos gastos sociais e dos investimentos públicos, aliadas aos mecanismos de apoio ao capital privado e de defesa do crescimento e à ampliação da oferta de crédito que, em conjunto, sustentaram a retomada do PIB com melhor distribuição de renda.

O olhar atento revela que o Governo Lula, ao mesmo tempo em que se manteve fiel à convenção macroeconômica tradicional, em resposta a um conjunto variado de interesses solidamente consolidados na sociedade brasileira, criou espaços para as políticas de caráter social, cumprindo promessas de campanha (ERBER, 2011). O governo, em verdade, soube servir simultaneamente a dois senhores e manter apoios de diferentes setores, combinando o sucesso em garantir o crescimento do PIB com a distribuição de renda, sem descuidar dos interesses da camada mais alta de renda.

\section{CONSIDERAÇÕES FINAIS}

Os pressupostos do NCM estão presentes no ideário dos formuladores de políticas públicas no Brasil desde a implantação do Plano Real e a mudança ocorrida no segundo governo Lula foi, de certa forma, "sancionada" internacionalmente. No contexto da crise mundial, a necessidade de socorrer os países dos efeitos da recessão deu lugar às propostas de revisão da teoria dominante, com a ampliação das ações de política fiscal. O chamado do mainstream em defesa de políticas fiscais ativas durante a crise se justificava diante da insuficiência dos mecanismos monetários em lidar com os aspectos "estritamente financeiros" e com seus desdobramentos sobre a economia real. O mainstream passou a reconhecer que, em casos excepcionais (sic), quando a política monetária perde a eficácia, a política fiscal deve ser acionada, de maneira pontual, para estimular a atividade e ajudar na estabilização econômica, dada a sua capacidade de atuação na demanda agregada ${ }^{46}$ (BERNANKE, 2002; KRUGMAN, 2005).

As mudanças na área fiscal realizadas no governo Lula foram apreendidas, no primeiro momento, como medidas exploratórias das possibilidades presentes no arcabouço convencional e passaram a ser criticadas quando se tornou evidente que os

\footnotetext{
46 Segundo Santos (2011, p. 85), "em tempos de taxas de juros muito baixas, crises severas (principalmente de deflação) ou no caso de países pertencentes a uniões monetárias (notadamente a União Europeia) sofrerem choques individuais, a política fiscal pode entrar em cena atuando no ajuste da demanda agregada”.
} 
efeitos internos da crise haviam sido superados e a estratégia, pensada como temporária pelos simpatizantes do modelo teórico da NCM, não se alterou. De fato, as medidas adotadas desde 2006 revelaram alterações do comportamento do governo em favor de políticas de caráter desenvolvimentista.

A novidade colocou-se na adoção de um conjunto de ações de maior envolvimento do Estado no fomento ao crescimento, em substituição à estratégia anterior de privilegiar o papel do mercado no projeto de desenvolvimento. As mudanças não podem ser confundidas com o descomprometido das regras do regime fiscal, estabelecido mais de uma década antes, pois se manteve o compromisso de estabilidade da dívida pública e de solvência da situação fiscal, bem como as práticas orçamentárias e os limites de gestão fiscal definidos na LRF.

As críticas às mudanças intensificaram-se no governo Dilma, abrangendo desde os argumentos convencionais, como os de inchaço da máquina pública, de aumento dos gastos correntes até os referentes aos mecanismos usados na capitalização dos órgãos públicos ou na dinâmica de geração de superavit primário, que passou a ser conhecida como "contabilidade criativa" ${ }^{47}$. O maior clamor das críticas tem explicações de diferentes ordens, mas, no plano teórico, pode ser lido como o esforço conservador de, superado o momento mais agudo da crise, retornar ao conforto da visão convencional de defesa da ortodoxia fiscal ${ }^{48}$ e do fim de políticas desenvolvimentistas. $\mathrm{O}$ embate, mesmo no campo convencional, não alcançou o consenso e não estão certos os desdobramentos a serem incorporados nas ações efetivas de política fiscal.

Os últimos anos do governo Lula mostraram que, mesmo diante dos limites em alterar o tripé de política macroeconômica, é viável rever a forma de pensar a política fiscal, com a sua flexibilização em favor de medidas que coloquem o Estado como ator-chave na condução e no fomento do crescimento econômico.

Os avanços na gestão dos recursos públicos alcançados após a estabilização econômica não podem ser negados e permitiu melhor conhecimento sobre a realidade orçamentária, nem é o caso de negar que a adoção de regras fiscais limitam comportamentos espúrios e descompromissos com as contas públicas. O que deve ser colocado em discussão é que um modelo que respeite esses avanços pode também se valer de um Estado

${ }^{47} \mathrm{O}$ conceito refere-se ao fato do governo utilizar recursos oriundos de fora do que é considerado "setor público" no cálculo do resultado primário para aumentar seu superavit. Os instrumentos, presentes desde 2010, englobam pagamentos de dividendos ao Tesouro por empresas fora do conceito de setor público, venda de patrimônio público e empréstimos a empresas estatais também fora do conceito, antecipação de receitas, criação de receita primária, pagamento de despesas com títulos da dívida pública e mesmo o adiamento dos pagamentos, aumentando a rubrica "restos a pagar" de cada exercício orçamentário.

${ }^{48}$ Ver Barros (2010), Garcia (2010) e Mendes (2014), entre outros. 
mais presente na economia, cumprindo o papel de agente comprometido com crescimento econômico e redução das desigualdades sociais e econômicas. Os modelos que podem dar suporte teórico a essa visão existem, se recorremos, por exemplo, à contribuição recente da escola pós-keynesiana ${ }^{49}$. Além disso, a experiência recém adotada mostrou a viabilidade da estratégica, confirmada pelo crescimento econômico apresentado até 2010. A dificuldade está em arregimentar força política em favor de um programa em condições de defender a opção do desenvolvimentismo social e de enfrentar as amarras antepostas ao avanço de um país com melhor distribuição de renda.

\section{REFERÊNCIAS BIBLIOGRÁFICAS}

ALLSOPP, C.; VINES, D. The macroeconomic role of fiscal policy. Oxford Review of Economic Policy, v. 21, n. 4, p. 485-508, 2005.

ARESTIS, P. "What is the new consensus in macroeconomics?". In: ARESIS, P. (Ed.). Is there a New Consensus in Macroeconomics? London: Palgrave MacMillan. 2007.

ARESTIS, P. New consensus macroeconomics: a critical appraisal. Levy Economics Institute Working Paper, n. 564, 2009.

ARESTIS, P.; SAWYER, M. New consensus, New Keynesianism, and the economics of the third way. Levy Economics Institute Working Paper, n. 364, 2002.

ARESTIS, P.; SAWYER, M. On the effectiveness of monetary policy. Levy Economics Institute Working Paper, n. 369, 2003a.

ARESTIS, P.; SAWYER, M. Reinventing fiscal policy. Levy Economics Institute Working Paper, n. 381, 2003b.

ARESTIS, P.; SAWYER, M. The case for fiscal policy. Levy Economics Institute Working Paper, n. $382,2003 \mathrm{c}$.

BACHA, E. L. O fisco e a inflação: uma interpretação do caso brasileiro. Revista de Economia Política, v. 14, n. 1, p. 5-17, 1994.

BALTAR, P.; SOUEN, J.; CAMPOS, G. Emprego e distribuição de renda. Texto para Discussão, Campinas, IE-UNICAMP, n. 298, 2017.

BARBOSA, N.; SOUZA, J. A. P. “A inflexão do Governo Lula: política econômica, crescimento e distribuição de renda”. In: SADER, E.; GARCIA, M. A. (Orgs). Brasil: Entre o passado e o futuro. São Paulo: Boitempo, 2010.

BARRO, R. Are government bonds net wealth? Journal of Political Economy, v. 82, n. 6, p. 10951117, 1974.

${ }^{49}$ Como Setterfield (2005), Fontana (2009b) e Tcherneva (2011a; 2011b; 2012a; 2012b). 
BARRO, R.; GORDON, D. Rules, discretion and reputation in a model of monetary policy. NBER Working Paper, n. 1079, 1983.

BARROS, L. C. M. Arredondando o debate sobre o BNDES. Valor Econômico, Opinião, A13, 16 ago. 2010.

BELLUZZO, L. O declínio de Bretton Woods e a emergência dos mercados globalizados. Economia e Sociedade, Campinas, n. 1, v. 4, jun. 1995.

BERNANKE, B. Deflation: making sure "it" doesn't happen here. Remarks Before the National Economists Club. Washington, D.C, 2002.

BLANCHARD, O. The state of macro. NBER Working Paper, n. 14.259, 2008.

BLANCHARD, O.; DELL'ARICCIA, G.; MAORO, P. Rethinking Macroeconomic Policy. IMF Staff Position Note, n. 10/03, 2010.

BLANCHARD, O.; DELL'ARICCIA, G.; MAORO, P. Rethinking Macro Policy II: Getting Granular. IMF Staff Position Note, n. 13/03, 2013.

BLANCHARD, O.; SUMMERS, L. Rethinking stabilization policy. Back to the future. Peterson Institute for Intersternal Economics, 2017. Disponível em: <https://piie.com/system/files/ documents/blanchard-summers20171012paper.pdf>. Acesso em: 1 out. 2017.

BLINDER, A. The case against the case against discretionary fiscal policy. Center for Economic Policy Studies Working Papers, University of Princeton, n. 102, jun. 2004.

BRASIL. Política econômica e reformas estruturais. Brasília, DF: Ministério da Fazenda, Secretaria de Política Economia, 2003.

CARLIN, W.; SOSKICE, D. Macroeconomics: imperfections, institutions and policies. Oxford: Oxford University Press, 2006.

CLAESSENS, S. et al. Lessons and policy implications from the global financial crisis. IMF Working Paper, n. 10/44, 2010.

CLARIDA, R.; GALI, J.; GERTLER, M. The Science of monetary policy: a new Keynesian perspective. Journal of Economic Literature, v. 37, n. 4, p. 1661-707, dez. 1999.

DELFIM NETTO, A. Déficit nominal zero. Boletim de Conjuntura \& Tecnologia, UFPR, n. 1, v. 2, jul./ago. 2005.

DEVEREUX, M. Fiscal deficits, debt, and monetary policy in a liquidity trap. Federal Reserve Bank of Dallas Globalization and Monetary Policy Institute Working Paper, n. 44, abr. 2010.

EGGERTSSON, G. What fiscal policy is effective at zero interest rates? Federal Reserve Bank of New York Staff Report, n. 402, 2009.

EICHENGREEN, B. "Macroeconomic and financial policies before and after the crisis". In: OBSTFELD, M.; CHO, D.; MASON, A. (Eds.). Global economic crisis impacts, transmission and recovery: Impacts, transmission and recovery. Cheltenham, UK; Northampton, MA: Edward Elgar, 2012.

ERBER, F. As convenções de desenvolvimento no governo Lula: um ensaio de economia política. Rev. Econ. Política, v. 31, n. 1, p. 31-55, 2011.

FILGUEIRAS, L. História do Plano Real. São Paulo: Boitempo Editorial, 2000. 
FONTANA, G. Whither New Consensus Macroeconomics? The role of government and fiscal policy in modern macroeconomics. Levy Economics Institute Working Paper, n. 563, 2009a.

FONTANA, G. "Fiscal policy in today's endogenous money world”. In: CREEL, J.; SAWYER, M. (Eds.). Current thinking on fiscal policy. London: Palgrave Macmillan, 2009b.

FORDER, J. The historical place of the Friedman-Phelps' expectation critique. Department of Economics Discussion Paper Series, University of Oxford, n. 399, 2007.

FRIEDMAN, M. The role of monetary policy. The American Economic Review, v. 58, n. 1, p. 1-17, mar. 1968.

GARCIA, M. G. P. Contabilidade criativa e risco fiscal. Valor Econômico, Opinião, A15, 17 set. 2010.

GIAMBIAGI, F. Uma agenda fiscal para 2007-2010. Texto para Discussão, IPEA, Rio de Janeiro, n. 1123, out. 2005.

GIAVAZZI, F; PAGANO, M. "Can severe fiscal contraction be expansionary?” In: BLANCHARD, O.; FISCHER, S. (Eds.). NBER Macroeconomics Annual, 1990.

GOBETTI, S. W.; SCHETTINI, B. P. Dívida Líquida e dívida bruta: uma abordagem integrada para analisar a trajetória e o custo do endividamento brasileiro. Texto para Discussão, IPEA, Brasília, n. 1514, dez. 2010.

GOLDFAJN, I.; GUARDIA, E. Regras fiscais e sustentabilidade da dívida no Brasil. Notas Técnicas do Banco Central do Brasil, n. 39, jul. 2003.

GOMES, G.; CRUZ, C. Vinte anos de Economia Brasileira: Atualização. Brasília: Centro de Altos Estudos Brasil Século XXI, 2017.

GOODFRIEND, M.; KING, R. G. The New neoclassical synthesis and the role of monetary policy. NBER Macroeconomics Annual, v. 12, p. 231-283, 1997.

GUARDIA, E. R. O regime fiscal brasileiro. Tese (Doutorado em Economia) - Faculdade de Economia, Administração e Contabilidade, Universidade de São Paulo, São Paulo, 1999.

GUARDIA, E. R. “As razões do ajuste fiscal”. In: GIAMBIAGI, F.; REIS, J. G.; URANI, A. (Orgs.). Reformas no Brasil: balanço e agenda. Rio de Janeiro: Nova Fronteira, 2004.

HELLER, P. S. Considering IMF's perspective on a "sound fiscal policy". IMF Discussion Paper, n. 02/08, jul. 2002.

HIRATUKA, C.; SARTI, F. Investimento direto e internacionalização de empresas brasileiras no período recente. Textos para Discussão, IPEA, Brasília, n. 1610, 2011.

HIRATUKA, C.; SARTI, F. Transformações na estrutura produtiva global, desindustrialização e desenvolvimento industrial no Brasil. Revista de Economia Política, v. 37, n. 1, p. 189-207, 2017.

KING, R. G. Quantitative theory and econometrics. Federal Reserve Bank of Richmond Economic Quarterly, p. 53-105, summer 1995

KIRSANOVA, T.; STEHN, S.; VINES, D. The interactions between fiscal policy and monetary policy. Oxford Review of Economic Policy, v. 21, n. 4, p. 532-64, 2005.

KYDLAND, F. E.; PRESCOTT, E. C. Rules rather than discretion: the inconsistency of optimal plans. The Journal of Political Economy, v. 85, n. 3, p. 473-492, 1977. 
KRUGMAN, P. Is fiscal policy poised for a comeback? Oxford Review of Economic Policy, v. 21, n. 4, p. 515-523, 2005.

LEEPER, E. Equilibria under "active" and "passive" monetary and fiscal policies. Journal of Monetary Economics, v. 27, n. 1, p. 129-147, 1991.

LEEPER, E.; WALKER, T. “Perceptions and misperceptions of fiscal inflation”. In: ALESINA, A.; GIAVAZZI, F. (Eds.). Fiscal Policy after the financial crisis. Chicago: National Bureau of Economic Research Conference Report, Chicago Press, 2013.

LOPREATO, F. Novos tempos política fiscal e condicionalidades pós-80. Revista de Economia Contemporânea, v. 8, n. 1, p. 125-154, jan./jun. 2004.

LOPREATO, F. O papel da política fiscal: um exame da visão convencional. Texto para Discussão, IE-UNICAMP, Campinas, n. 119, fev. 2006a.

LOPREATO, F. "Política fiscal: mudanças e perspectivas”. In: CARNEIRO, R. (Org.) A supremacia dos mercados e a política econômica do governo Lula. São Paulo: UNESP, 2006b.

LOPREATO, F. Caminhos da política fiscal do Brasil. São Paulo: UNESP, 2013.

LOPREATO, F.; DEDECCA, C. Os desafios de um padrão de investimento para o crescimento com redução da desigualdade no Brasil. Texto para Discussão, IE-UNICAMP, Campinas, $\mathrm{n}$. 223, 2013.

LUCAS, R. E. Jr. "Econometric policy evaluation: a critique”. In: BRUNNER, K.; MELTZER, A. The Phillips Curve and labor markets. New York: Elsevier, 1976, p. 19-46.

MCCALLUM, B. T. Monetary policy analysis in models without money. Federal Reserve Bank of St. Louis Review, v. 83, n. 4, p. 145-160, jul./ago. 2001.

MEYER, L. H. Does money matter? Federal Reserve Bank of St. Louis Review, v. 83, n. 5, p. 1-15, 2001.

MENDES, M. O que é contabilidade criativa? [Online] Brasil Economia e Governo, 2014. Disponível em: <www.brasil-economia-governo.org.br/?p=2132>. Acesso em: 16 out. 2015:

ORAIR, R. Investimento público no Brasil: trajetória e relações com o regime fiscal. Textos para Discussão, IPEA, Brasília, n. 2215, 2016.

PRATES, D. M. O regime cambial brasileiro de 1999 a 2008. Textos para Discussão, CEPAL-IPEA, Brasília, n. 12, 2010.

SANTOS, F. A. A nova síntese neoclássica frente à crise econômica mundial: a volta da política fiscal? Dissertação (Mestrado em Economia) - Instituto de Economia, Universidade Estadual de Campinas, Campinas, 2011.

SARGENT, T.; WALLACE, N. Some unpleasant monetarist arithmetic. Federal Reserve Bank of Minneapolis Quaternaly Review, 1981.

SETTERFIELD, M. Is there a stabilizing role for fiscal policy in the new consensus? Dublin: Department of Economics at Trinity College, University of Dublin, 2005.

SNOWDON, B.; VANE, H. R. Modern Macroeconomics: its origins, development and current state. Northampton, MA: Edward Elgar, 2005

SOLOW, R. M. Rethinking fiscal policy. Oxford Review of Economic Policy, v. 21, n. 4, p. 509-514, 2005. 
TAVARES, M. Vinte anos de política fiscal no Brasil: dos fundamentos do novo regime à Lei de Responsabilidade Fiscal. Revista de Economia \& Relações Internacionais, v. 4, n. 7, jul. 2005.

TAYLOR, J. B. Discretion versus policy rules in practice. Carnegie-Rochester Conference Series on Public Policy, v. 39, n. 1, p. 195-214, 1993.

TCHERNEVA, P. The Return of fiscal policy: can the new developments in the new economic consensus be reconciled with the post-Keynesian view? Levy Economics Institute Working Paper, n. 539, 2008.

TCHERNEVA, P. Fiscal policy effectiveness: lessons from the great recession. Levy Economics Institute Working Paper, n. 649, 2011 a.

TCHERNEVA, P. Fiscal Policy: why aggregate demand management fails and what to do about it. Levy Economics Institute Working Paper, n. 650, 2011 b.

TCHERNEVA, P. Permanent on-the-spot job creation: the missing Keynes plan for full employment and economic transformation. Review of Social Economy, v. 70, n. 1, p. 57-80, 2012a.

TCHERNEVA, P. Reorienting fiscal policy after the great recession. Levy Economics Institute Working Paper, n. 719, 2012b.

VARGAS, N. C. Estados no Brasil e o controle fiscal e financeiro pela União no pós-Real. Tese (Doutorado em Economia) - Instituto de Economia, Universidade Estadual de Campinas, Campinas, 2006.

VELLOSO, R. "Escancarando o problema fiscal: é preciso controlar o gasto não financeiro obrigatório da União”. In: VELLOSO, R. (Org.) Por que o Brasil não é um país de alto crescimento? Rio de Janeiro: José Olympio, 2006.

WOODFORD, M. Interest and prices: foundations of a theory of monetary policy. Princeton: Princeton University Press, 2003.

WOODFORD, M. Convergence in macroeconomics: elements of the new synthesis. Remarks for a panel discussion at the AEA meeting. Jan. 2008. Disponível em <http://www.columbia. edu/ mw2230/Convergence_AEJ.pdf $>$. Acesso em: 16 out. 2015. 